Int. J. Electrochem. Sci., 14 (2019) 4047 - 4056

\title{
The Pitting Corrosion Behavior of Copper with Different Grain Size
}

\author{
Yanhui Ma ${ }^{1, *}$, Xiaoxuan Tian ${ }^{2}$, Jianfeng Yin ${ }^{1}$, Junping Chen ${ }^{1}$, Jianan Jiang ${ }^{3, *}$ \\ ${ }^{1}$ North China Electric Power Institute Co.,Ltd, Beijing 100045, China \\ ${ }^{2}$ Xi' an Thermal Power Research Institute Co.,Ltd, Xi' an 710003, China \\ ${ }^{3}$ Department of materials science and engineering, University of sheffield, Sheffield, S1 3JD, UK \\ *E-mail: mayanhui1985@163.com, 420030973@qq.com
}

doi: $10.20964 / 2019.05 .11$

Received: 3 January 2019 / Accepted: 13 February 2019 / Published: 10 April 2019

In this paper, the pitting corrosion behaviours of copper materials with different grain sizes (average grain sizes of 23,67 , and $470 \mu \mathrm{m}$ ) were investigated based on cyclic polarization and electrochemical impedance spectroscopy (EIS). The results showed that a very protective passive film without any pitting can be observed in $\mathrm{NaOH}$ solutions. The pitting corrosion behaviours were observed in a $\mathrm{Na}_{2} \mathrm{SO}_{4}$ solution and a $\mathrm{Na}_{2} \mathrm{SO}_{4}+\mathrm{NaOH}$ solution. The pitting susceptibility of copper decreased with the increasing grain size in the $\mathrm{Na}_{2} \mathrm{SO}_{4}$ solution due to a decrease in the electrochemically active surface area. In contrast, the pitting susceptibility increased with increasing copper grain size in the $\mathrm{Na}_{2} \mathrm{SO}_{4}+$ $\mathrm{NaOH}$ solution, which was related to a decrease in the quality of the formed passive film.

Keywords: Copper; Pitting corrosion; Grain size; Cyclic polarization; Electrochemical impedance spectroscopy

\section{$\underline{\text { FULL TEXT }}$}

(C) 2019 The Authors. Published by ESG (www.electrochemsci.org). This article is an open access article distributed under the terms and conditions of the Creative Commons Attribution license (http://creativecommons.org/licenses/by/4.0/). 